\title{
Clinical and laboratory profile of pediatric and adolescent patients with type 1 diabetes
}

\author{
Laura Pereira da Silva Jose, ${ }^{1}$ Adriane de A. Cardoso-Demartini, ${ }^{1}$ Raphael D. R. Liberatore Junior, ${ }^{1}$ \\ Maria Fernanda Vanti Macedo Paulino, ${ }^{2}$ Sofia Helena Valente de Lemos-Marini, ${ }^{2}$ \\ Gil Guerra-Júnior, ${ }^{2}$ Albertina Gomes Rodrigues ${ }^{3}$
}

\begin{abstract}
Objective: To evaluate clinical and laboratory profiles of patients with type 1 diabetes mellitus in three public hospitals in São Paulo, Brazil, since type 1 diabetes mellitus is a chronic illness that occurs mainly in the pediatric age group in the Brazilian population.

Methods: Cross-sectional study with patients followed up in reference centers in São José do Rio Preto (FAMERP), Campinas (UNICAMP) and São Paulo (Conjunto Hospitalar do Mandaqui). Data about gender, age, diabetes duration, daily insulin dose, number of daily insulin injections, and glycosylated hemoglobin $\left(\mathrm{HbA}_{1 \mathrm{c}}\right)$ were analyzed.

Results: Two hundred and thirty-nine patients (131 females) were evaluated; mean age was $13.1 \pm 4.7$ years and mean diabetes duration was $6.6 \pm 4.2$ years. Daily insulin doses ranged from 0.1 to $1.78 \mathrm{units} / \mathrm{kg} / \mathrm{day}(0.88 \pm 0.28)$, and $180(74.7 \%)$ patients had two daily injections. $\mathrm{HbA}_{1 \mathrm{c}}$ ranged from 4.6 to $17.9 \%(10.0 \pm 2.3 \%)$.

Conclusions: Although the hospitals included in this study are excellence centers for the follow-up of patients with diabetes in three municipalities in the state of São Paulo, one of the most developed states in Brazil, blood glucose control evaluated according to $\mathrm{HbA}_{1 \mathrm{c}}$ was not adequate. Findings confirm that, despite the efforts of all the professionals involved, great challenges still lie ahead.
\end{abstract}

J Pediatr (Rio J). 2009;85(6):490-494: Diabetes mellitus, type 1 diabetes, insulin, glycosylated hemoglobin.

\section{Introduction}

Type 1 diabetes mellitus (T1DM) is one of the most serious endocrine diseases of childhood and adolescence. Its incidence, which varies between countries and different ethnic groups, ranges from 0.1 to $37.4 / 100,000$ among children 0 to 14 years. ${ }^{1}$

The purpose of diabetes treatment is to achieve metabolic balance and to ensure patient well being. Evidence shows that improved blood glucose control reduces the risk of chronic complications and is associated with better quality of life. ${ }^{2}$

Intensive insulin regimens have been suggested, but their use alone does not ensure that expected optimal blood glucose control is achieved. Factors such as diabetes education, support of healthcare team, self-monitoring, and patient's satisfaction may be more importantly associated with improved disease control than intensive treatment. ${ }^{3}$

1. Department of Pediatrics and Pediatric Surgery, Pediatric Endocrinology Section, Faculdade de Medicina de São José do Rio Preto (FAMERP), São José do Rio Preto, SP, Brazil.

2. Department of Pediatrics, Pediatric Endocrinology Unit, School of Medicine, Universidade Estadual de Campinas (UNICAMP), Campinas, SP, Brazil.

3. Department of Pediatrics, Pediatric Endocrinology Unit, Conjunto Hospitalar do Mandaqui, São Paulo, SP, Brazil.

No conflicts of interest declared concerning the publication of this article.

Suggested citation: Jose LP, Cardoso-Demartini AA, Liberatore Junior RD, Paulino MF, de Lemos-Marini SH, Guerra-Júnior G, et al. Clinical and laboratory profile of pediatric and adolescent patients with type 1 diabetes. J Pediatr (Rio J). 2009;85(6):490-494.

Manuscript submitted Jun 18 2009, accepted for publication Aug 262009.

doi:10.2223/JPED.1942 
The recommendations made in the Diabetes Control and Complications Trial (DCCT) demand important changes in patient's behavior: self-monitoring of capillary blood glucose three to four times a day, four daily insulin injections or use of an insulin pump, changes in eating habits, practice of planned physical activities, and adjustment of insulin doses according to dietary intake and exercise. ${ }^{4}$

The DCCT demonstrated that intensive treatment of 13to 39-year-old patients delays the onset and progression of retinopathy, nephropathy and diabetic neuropathy, and that there is an association between blood glucose levels, glycosylated hemoglobin $\left(\mathrm{HbA}_{1 \mathrm{c}}\right)$ and microvascular complications in patients with diabetes. ${ }^{4}$ Hypoglycemia is a limiting factor to intensive glycemic control, especially in small children who are under risk of cognitive alteration after repetitive hypoglycemic episodes. ${ }^{5}$ Although the risk of hypoglycemia was greater in patients undergoing intensive therapy, benefits outweighed the risk of hypoglycemia6-8 and now the basal-bolus regimen with rapid-acting analogs (aspart, lispro) given in bolus generally reduce hypoglycemia episodes and postprandial glycemia levels, while basal insulin analogs (detemir, glargina) tend to reduce particularly the number of episodes of nocturnal hypoglycemia. ${ }^{5}$

Intensive diabetes treatment is based on the adaptation of insulin regimens to the results of blood glucose selfmonitoring, and should not be determined only by the number of daily insulin injections. ${ }^{9}$ Strict clinical and laboratory control and individualized treatment should be determined by a multidisciplinary team. Moreover, patients and their families should receive education about the treatment and be prepared to adhere to it.

This study, which was conducted to improve patient follow-up, evaluated the clinical and laboratory profiles of children and adolescents with T1DM in three public hospitals that are excellence centers for patients with T1DM in the state of São Paulo, Brazil.

\section{Patients and methods}

This cross-sectional study was conducted in the middle of 2006, with patients followed up in T1DM reference centers in São José do Rio Preto (FAMERP), Campinas (UNICAMP) and São Paulo (Conjunto Hospitalar do Mandaqui). In those three centers, a multidisciplinary approach was used, as pediatric endocrinologists, nurses, nutritionists, psychologists, and educators work together in consultations four times a year, free emergency and telephone access. The follow-up was carried out beginning with the group meeting with the team and subsequently individual appointment with the doctor.

All patients and at least one caregiver received individual orientation from the professionals of the team (psychologist, nutritionist and nurse) relative to use of insulin, finger glycemic tests and food plan. There was no orientation as to carbohydrate counting.

The patients were encouraged to alter their insulin dosage based on the results of glycemic tests. Ophthalmologic evaluation and $24 \mathrm{~h}$ microalbuminuric dosages were carried out annually in those with more than 5 years of diabetes.

The diagnosis of T1DM was made following international criteria and excluded all other kinds of diabetes. No patient had retinopathy or nephropathy.

For all patients NPH insulin, syringes and glucose monitor strips are provided by the State. Insulin analogues, pumps and pens are not provided.

The medical records of 239 patients were reviewed, and data were collected about gender, age, disease duration, daily insulin dose, number of daily insulin injections, use of glucometer for self-monitoring of blood glucose levels, and level of $\mathrm{HbA}_{1 \mathrm{c}}$. All data were collected from the last visit records.

Level of $\mathrm{HbA}_{1 \mathrm{c}}$ was measured by high performance liquid chromatography (HPLC) at a reference interval of 4.6 to $6.5 \%$. According to the International Society of Pediatric and Adolescent Diabetes (ISPAD), optimal $\mathrm{HbA}_{1 \mathrm{c}}$ levels are $\leq 7.5 \%$; suboptimal, between 7.6 and $9.0 \%$; and poor (or high risk), greater than $9.0 \% .{ }^{4,9}$ For statistical analysis in this study, results were divided into two groups: poor control = $\mathrm{HbA}_{1 \mathrm{c}}>9.0 \%$; and good control $=\mathrm{HbA}_{1 \mathrm{c}} \leq 9.0 \%$.

The research protocol was approved by the Institutional Review Board from São José do Rio Preto Medical School with no necessity of a consent form.

Data were described and analyzed with a parametric test (Student's $t$ ), and with a nonparametric test (chisquare) for non-normally distributed values. Linear and multiple regression tests were used to study the behavior of two or more variables simultaneously to detect possible associations between variation of one variable as a function of variation of one or more of the other variables. The level of type I error was $\alpha=5 \%$, and $p<0.05$ was considered significant.

\section{Results}

The medical records of 239 patients ( 131 female patients) were reviewed. Mean age was $13.1 \pm 4.7$ years ( 3.0 to 26.2 years), and mean T1DM duration was $6.6 \pm 4.2$ years $(0.4$ to 18.5 years).

Insulin doses ranged from 0.1 to 1.78 units $/ \mathrm{kg} /$ day $(0.88 \pm 0.28)$. The number of daily insulin injections was two for $179(74.9 \%)$ patients, one for $28(11.7 \%)$, and three for 32 (13.4\%).

Sixty-four patients (26.8\%) used only NPH insulin; 78 (32.6\%) used premixed insulin (70/30; 80/20; 90/10); 44 (18.4\%) used NPH and regular insulin; and 52 (21.8\%), 
used NPH and lispro insulin. Only one patient (0.4\%) used glargine and lispro insulin.

Only two patients $(0.8 \%)$ did not perform capillary blood glucose self-monitoring because they did not have a glucometer at home.

$\mathrm{HbA}_{1 \mathrm{c}}$ ranged from 4.6 to $17.9 \%(10.0 \pm 2.3 \%)$, and there were no significant differences between genders (females $=10.1 \pm 2.4 \%$; males $=9.9 \pm 2.2 \% ; p=0.49$ ). T1DM control was good for $93(38.9 \%)$ patients, and poor for $146(61.1 \%)$. In both groups, most patients had two daily insulin injections (Table 1), and, unexpectedly, patients that had three daily injections had a greater mean $\mathrm{HbA}_{1 \mathrm{c}}(\mathrm{p}=0.007)$.

However, $\mathrm{HbA}_{1 \mathrm{c}}$ was significantly lower in patients that used NPH insulin and lispro than in patients that used only $\mathrm{NPH}$, premixed insulin or NPH and regular insulin $(p=0.0005)$ (Table 2$)$.

In this group, multiple regression analysis revealed that three daily injections $(p=0.008)$, doses greater than 0.8 units $/ \mathrm{kg} /$ day $(p=0.001)$, and disease duration longer than 5 years $(p=0.04)$ were associated with poorer T1DM control as assessed by level of $\mathrm{HbA}_{1 \mathrm{c}}$.

Table 1 - Distribution of patients with diabetes according to $\mathrm{HbA}_{1 \mathrm{c}}$ level

\begin{tabular}{lcc}
\hline T1DM control $\left(\mathbf{H b A}_{\mathbf{1 c}}\right)$ & Good $\mathbf{( \leq \mathbf { 9 . 0 } \% )}$ & Poor (> 9.0\%) \\
\hline Number of patients & $93(38.9 \%)$ & $146(61.1 \%)^{*}$ \\
Gender & 44 males, 55 females & 64 males, 82 females \\
Age (years) & $11.9 \pm 5.3(3.0-23.2)$ & $13.8 \pm 4.1(3.00-22.6)$ \\
T1DM duration (years) & $5.7 \pm 4.2(0.4-17.2)$ & $7.2 \pm 4.1(0.5-18.5)$ \\
Daily insulin dose (units/kg/day) & $0.85 \pm 0.28(0.17-1.78)$ & $0.90 \pm 0.27(0.10-1.68)$ \\
HbA $_{1 \mathrm{C}}$ (\%) & $7.8 \pm 1.0(4.6-9.0)$ & $11.4 \pm 1.8(9.1-17.9)^{*}$ \\
One daily injection & $18(19.4 \%)$ & $10(6.8 \%)$ \\
Two daily injections & $65(69.9 \%)$ & $114(78.1 \%)$ \\
Three daily injections & $10(10.7 \%)$ & $22(15.1 \%)^{*}$ \\
\end{tabular}

$\mathrm{HbA}_{1 \mathrm{c}}=$ glycosylated hemoglobin; $\mathrm{T} 1 \mathrm{DM}=$ type 1 diabetes mellitus.

${ }^{*} p<0.05$

Table 2 - Distribution of patients with diabetes according to type of insulin

\begin{tabular}{|c|c|c|c|c|}
\hline Type of insulin & $\begin{array}{l}\text { Only NPH } \\
(n=64)\end{array}$ & $\begin{array}{l}\text { Premixed } \\
(n=78)\end{array}$ & $\begin{array}{c}\text { NPH + Regular } \\
(n=44)\end{array}$ & $\begin{array}{c}\text { NPH + Lispro } \\
(\mathbf{n}=\mathbf{5 2})\end{array}$ \\
\hline Gender & $\begin{array}{l}30 \text { males, } \\
34 \text { females }\end{array}$ & $\begin{array}{l}37 \text { males, } \\
41 \text { females }\end{array}$ & $\begin{array}{l}17 \text { males, } \\
27 \text { females }\end{array}$ & $\begin{array}{l}24 \text { males, } \\
28 \text { females }\end{array}$ \\
\hline Age (years) & $\begin{array}{l}12.9 \pm 4.4 \\
(3.2-23.2)\end{array}$ & $\begin{array}{l}12.6 \pm 4.5 \\
(3.8-22.6)\end{array}$ & $\begin{array}{l}17.0 \pm 4.2 \\
(8.1-26.2)\end{array}$ & $\begin{array}{l}10.8 \pm 3.6 \\
(3.0-19.0)\end{array}$ \\
\hline T1DM duration (years) & $\begin{array}{c}6.7 \pm 4.2 \\
(0.4-17.2)\end{array}$ & $\begin{array}{l}7.1 \pm 4.4 \\
(0.8-18.5)\end{array}$ & $\begin{array}{l}8.5 \pm 3.6 \\
(0.7-16.0)\end{array}$ & $\begin{array}{c}4.1 \pm 3.0 \\
(0.5-10.0)\end{array}$ \\
\hline $\begin{array}{l}\text { Daily insulin dose } \\
\text { (units } / \mathrm{kg} / \text { day) }\end{array}$ & $\begin{array}{c}0.76 \pm 0.25 \\
(0.17-1.39)\end{array}$ & $\begin{array}{c}0.88 \pm 0.21 \\
(0.56-1.78)\end{array}$ & $\begin{array}{c}0.97 \pm 0.29 \\
(0.36-1.68)\end{array}$ & $\begin{array}{c}0.96 \pm 0.32 \\
(0.10-1.64)\end{array}$ \\
\hline One daily injection & $8(12.5 \%)$ & $0(0)$ & $0(0 \%)$ & $19(36.5 \%)$ \\
\hline Two daily injections & $53(82.8 \%)$ & $68(87.2 \%)$ & $27(61.4 \%)$ & $29(55.8 \%)$ \\
\hline Three daily injections & $3(4.7 \%)$ & $10(12.8 \%)$ & $17(38.6 \%)$ & $4(7.7 \%)$ \\
\hline $\mathrm{HbA}_{1 \mathrm{c}}(\%)$ & $\begin{array}{c}10.5 \pm 2.7 \\
(5.5-17.9)\end{array}$ & $\begin{array}{l}10.5 \pm 1.9 \\
(7.2-14.9)\end{array}$ & $\begin{array}{l}10.0 \pm 2.1 \\
(6.8-16.9)\end{array}$ & $\begin{array}{c}8.7 \pm 2.1 \\
(4.6-14.5)^{*}\end{array}$ \\
\hline
\end{tabular}

$\mathrm{HbA}_{1 \mathrm{c}}=$ glycosylated hemoglobin; T1DM = type 1 diabetes mellitus.

${ }^{*} \mathrm{p}<0.05$ - ANOVA. 


\section{Discussion}

In recent years, the concept of metabolic control has gained importance in the analysis of onset and progression of chronic complications of diabetes, and the concept of dissociation between metabolic control and onset of these complications was left behind in the history of diabetology. The DCCT concluded that there is a reduction of about $60 \%$ in the risk of retinopathy, nephropathy and diabetic neuropathies in patients with good control. ${ }^{4}$ Recent studies also found a reduction of $42 \%$ in cardiovascular risk in patients that undergo intensive treatment for diabetes mellitus. ${ }^{10}$ Moreover, each $1 \%$ reduction in the levels of $\mathrm{HbA}_{1 \mathrm{c}}$ significantly affects the prevention of microvascular complications. ${ }^{11}$

The objective of diabetes treatment is to keep $\mathrm{HbA}_{1 \mathrm{c}}$ at a level that prevents occurrence of severe and frequent hypoglycemia. ${ }^{5}$ In this study, mean $\mathrm{HbA}_{1 \mathrm{c}}$ was $10.0 \pm 2.3 \%$, and most $(61.1 \%)$ patients had levels greater than $9.0 \%$. These findings indicate a high risk of chronic complications and poor metabolic control despite self-monitoring and the efforts of the multidisciplinary medical team that assisted the patients.

The international experience with this age is not very different. Recent surveys have shown that it is very difficult to maintain $\mathrm{HbA}_{1 \mathrm{c}}$ levels under the eights even in reference centers. A recent Brazilian survey showed that $90 \%$ of 979 young adults in different places around the country were not under good control. ${ }^{12,13}$

More than only type of insulin, number of insulin shots or finger glucose dosages seem to be important. The team approach, frequent educational meetings and also psychological issues are very important, mainly in the adolescent group. ${ }^{12,14,15}$

A great number of patients $(32.6 \%)$ used premixed insulins, which have already been reported to be associated with poor metabolic control in adolescents. ${ }^{11}$ However, mean $\mathrm{HbA}_{1 \mathrm{c}}$ in this group of patients was similar to that of patients that used only NPH or NPH and regular insulin. The group with the lowest mean $\mathrm{HbA}_{1 \mathrm{c}}$ was that of patients that used NPH and lispro insulin, which may be explained by lispro's greater efficacy in rapidly reducing postprandial glucose levels.

The same results were found in other studies. Use of $\mathrm{NPH}$ insulin with rapid analogues in the same shot reduces $\mathrm{HbA}_{1 \mathrm{c}}$ by reducing postprandial glucose levels. The best way to control T1DM patients is the basal/bolus approach, which was not being used in this study group. ${ }^{16,17}$

Most patients (74.9\%) had two daily insulin injections and those that had three injections had greater mean $\mathrm{HbA}_{1 \mathrm{c}}$. This is the group of patients in whom the disease duration was longer. We could speculate that as those patients were the oldest (adolescents), metabolic control was decreased by poor adherence to the treatment, as reported by other authors. ${ }^{15}$

\section{Conclusion}

Although this study was conducted with patients followed up in reference hospitals of three cities in one of the most developed Brazilian state, optimal blood glucose control, evaluated according to level of $\mathrm{HbA}_{1 \mathrm{c}}$, was not achieved when only the number of daily insulin injections or the daily insulin dose was increased. The data showed that multidisciplinary teams still face great challenges to prescribe individualized treatments that respond to the needs of each patient with T1DM, and suggest that education should be the basis of successful treatments.

We also believe that new approaches, such as multiple insulin doses, insulin pumps and carbohydrates counting, could be helpful in improving metabolic control. Economic and social issues must be confronted, a major challenge for coming years.

\section{References}

1. Karvonen M, Viik-Kajander M, Moltchanova E, Libman I, LaPorte R, Tuomilehto J. Incidence of childhood type 1 diabetes worldwide. Diabetes Mondiale (DiaMond) Project Group. Diabetes Care. 2000;23:1516-26.

2. Hoey H, Aanstoot HJ, Chiarelli F, Daneman D, Danne T, Dorchy $\mathrm{H}$ et al. Good metabolic control is associated with better quality of life in 2,101 adolescents with type 1 diabetes. Diabetes Care. 2001;24:1923-8.

3. Danne T, Mortensen HB, Hougaard P, Lynggaard H, Aanstoot HJ, Chiarelli $\mathrm{F}$ et al. Persistent differences among centers over 3 years in glycemic control and hypoglycemia in a study of 3,805 children and adolescents with type 1 diabetes from the Hvidøre Study Group. Diabetes Care. 2001;24:1342-7.

4. The effect of intensive treatment of diabetes on the development and progression of long-term complications in insulin-dependent diabetes mellitus. The Diabetes Control and Complications Trial Research Group. N Engl J Med. 1993;329:977-86.

5. Schmid H. New options in insulin therapy. J Pediatr (Rio J). 2007;83:S146-54.

6. Effect of intensive diabetes treatment on the development and progression of long-term complications in adolescents with insulindependent diabetes mellitus: Diabetes Control and Complications Trial. Diabetes Control and Complications Trial Research Group. Group. J Pediatr. 1994;125:177-88.

7. Epidemiology of severe hypoglycemia in the diabetes control and complications trial. The DCCT Research Group. Am J Med. 1991;90:450-9.

8. Hypoglycemia in the Diabetes Control and Complications Trial. The Diabetes Control and Complications Trial Research Group. Diabetes. 1997;46:271-86.

9. Malerbi D, Damiani D, Rassi N, Chacra AR, Niclewicz ED, Silva Filho $\mathrm{R}$ et al. Posição de consenso da Sociedade Brasileira de Diabetes - Insulinoterapia intensiva e terapêutica com bombas de insulina. Arq Bras Endocrinol Metab. 2006;50:125-35.

10. Rewers M, Pihoker C, Donaghue K, Hanas R, Swift P, Klingensmith GJ, et al. Assessment and monitoring of glycemic control in children and adolescents with diabetes. Pediatr Diabetes. 2007;8:408-18. 
11. Nathan DM, Cleary PA, Backlund JY, Genuth SM, Lachin JM, Orchard TJ et al. Intensive diabetes treatment and cardiovascular disease in patients with type 1 diabetes. N Engl J Med. 2005;353:2643-53.

12. Mortensen HB, Robertson KJ, Aanstoot HJ, Danne T, Holl RW, Hougaard $P$ et al. Insulin management and metabolic control of type 1 diabetes mellitus in childhood and adolescence in 18 countries. Hvidøre Study Group on Childhood Diabetes. Diabet Med. 1998;15:752-9.

13. Mendes AB, Fittipaldi JA, Neves RC, Chacra AR, Moreira ED Jr. Prevalence and correlates of inadequate glycaemic control: results from a nationwide survey in 6,671 adults with diabetes in Brazil. Acta Diabetol. In press 2009.

14. Eliaschewitz FG, Franco DR. Does brittle diabetes exist as a clinical entity? Arq Bras Endocrinol Metabol. 2009;53:466-9.

15. Akbaş S, Karabekiroğlu K, Ozgen T, Tasdemir G, Karakurt M, Senses $A$, et al. Association between emotional and behavioral problems and metabolic control in children and adolescents with Type 1 diabetes. J Endocrinol Invest. 2009;32:325-9.
16. Grossi SA, Lottenberg SA, Lottenberg AM, Della Manna T, Kuperman $\mathrm{H}$. Home blood glucose monitoring in type 1 diabetes mellitus. Rev Lat Am Enfermagem. 2009;17:194-200.

17. Crasto W, Jarvis J, Khunti K, Davies MJ. New insulins and new insulin regimens: a review of their role in improving glycaemic control in patients with diabetes. Postgrad Med J. 2009;85:257-67.

\section{Correspondence:}

Raphael D. R. Liberatore Junior

Rua Ondina, 54

CEP 15015-205 - São José do Rio Preto, SP - Brazil

Tel. : +55 (17) 3235.8026

E-mail: liberat@famerp.br 